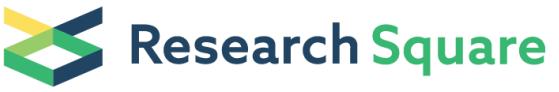 \\ Preprints are preliminary reports that have not undergone peer review. \\ They should not be considered conclusive, used to inform clinical practice, or referenced by the media as validated information.
}

\section{The Association Between Frailty and All-Cause Mortality in Community-Dwelling Older Individuals: An Umbrella Review}

\author{
A R M Saifuddin Ekram \\ Monash University Faculty of Medicine Nursing and Health Sciences https://orcid.org/0000-0003-4267- \\ 1286
}

Robyn Woods

Monash University SPHPM: Monash University School of Public Health and Preventive Medicine

\section{Carlene Britt}

Monash University SPHPM: Monash University School of Public Health and Preventive Medicine

\section{Sara E Espinoza}

UT Health San Antonio: The University of Texas Health Science Center at San Antonio

Michael E Ernst

UI Carver College of Medicine: The University of lowa Roy J and Lucille A Carver College of Medicine Joanne Ryan ( $\sim$ joanne.ryan@monash.edu )

Monash University SPHPM: Monash University School of Public Health and Preventive Medicine https://orcid.org/0000-0002-7039-6325

\section{Research article}

Keywords: All-Cause Mortality, Community-dwelling, Frailty Deficit Accumulation index, Fried Frailty Phenotype, Older population.

Posted Date: October 6th, 2020

DOI: https://doi.org/10.21203/rs.3.rs-84994/v1

License: (c) (7) This work is licensed under a Creative Commons Attribution 4.0 International License. Read Full License

Version of Record: A version of this preprint was published at Journal of Frailty \& Aging on January 1st, 2021. See the published version at https://doi.org/10.14283/jfa.2021.20. 


\section{Abstract}

Background Frailty is associated with multiple adverse health outcomes, including mortality. Several methods have been used to characterize frailty, each based on different frailty scales. These include scales based on a phenotype, multidomain, and deficit accumulations. Several systematic reviews have examined the association between frailty and mortality; however, it is unclear whether these different frailty scales similarly predict mortality. This umbrella review aims to examine the association between frailty assessed by different frailty scales and all-cause mortality among community-dwelling older adults.

Methods The umbrella review protocol was registered at PROSPERO, and it was conducted following the PRISMA statement. MEDLINE, Embase, PubMed, Cochrane Database of Systematic Reviews, Joanna Briggs Institute (JBI) EBP database, and Web of Science database was searched to identify systematic reviews and meta-analyses examining the association between frailty and all-cause mortality. Methodological quality was assessed using the JBI. Critical Appraisal Checklist and online AMSTAR-2 critical appraisal checklist. For eligible studies, essential information was extracted and synthesized qualitatively.

Results Five systematic reviews were included, with a total of 434,115 participants. Three systematic reviews focused on single frailty scales; one evaluated Fried physical frailty phenotype and its modifications; another focused on the deficit accumulation frailty index. The third evaluated the FRAIL (Fatigue, Resistance, Ambulation, Illness, and Loss of weight) scale. The two other systematic reviews determined the association between frailty and mortality using different frailty scales. All the systematic reviews performed metaanalyses and assessed between-study heterogeneity. All of the systematic reviews found that frailty was significantly associated with all-cause mortality.

Conclusion This umbrella review demonstrates that frailty is a significant predictor of all-cause mortality, irrespective of the specific frailty scale.

\section{Background}

Frailty is a geriatric syndrome characterized by reduced physiological reserves (1). It is associated with increased vulnerability to adverse outcomes such as falls, fractures, hospitalizations, institutionalizations, disability, dementia, lower quality of life, and mortality $(2,3)$. The prevalence of frailty varies across populations, according to age, gender, ethnicity, and socioeconomic status, and ranges from $5.8-35 \%$ in community settings $(4,5)$. The wide variation might result from differences in the frailty assessment scale applied, as different tools utilize different criteria to define and categorize frailty. The prevalence of frailty is expected to rise worldwide due to the rapidly growing aging population (6).

While the concept of frailty is widely recognized, there is no single explicit criterion to define frailty. In 2013 , a consensus statement by six major international scientific societies defined frailty as a medical syndrome with multiple causes and contributors that is characterized by diminished strength, endurance, and reduced physiologic function and increases an individual's vulnerability for developing disability, dependency, or death $(7,8)$. In this definition, frailty is viewed as firstly, a clinical entity different from disability, sarcopenia, or multimorbidity; secondly, it affects a person's physical or cognitive domains; and finally, it is considered as 
a dynamic state, which can improve or deteriorate over time (7). Besides, an intermediate or 'prefrail' stage has also been recognized $(3,9,10)$.

Several frailty scales have been developed to characterize frailty in older adults, described in three broad categories. The first category includes focused physical scales, which most notably contains the Fried physical frailty phenotype from the Cardiovascular Health Study, as well as adaptations derived from this original scale (3). It consists of five components: unintentional weight loss, muscle weakness, exhaustion or low energy level, slowness or slow gait, and low physical activity. Persons are frail if three or more of the five criteria are met. The second category of frailty scales is a multidomain scale (11), which describes multidimensional characteristics of frailty containing more than one medical, physical, cognitive, or environmental factors. The third type of scale is known as a deficit accumulation frailty index (12). It consists of an inventory of various deficits covering multiple domains or body systems and the percentage of deficits calculated.

These three types of scales capture different aspects of the frailty syndrome and, therefore, there may be differences in their association with health outcomes. Understanding these differences is important because it could inform the context in which the different measures are best applied. All three categories of frailty assessment scales have some limitations. For example, the phenotype scale does not cover all dimensions of frailty, such as cognition or affect (3). The multidomain scale and the deficit accumulation model-based scales are comprehensive but time-consuming. Clinical information may not be readily available for all individual components, and consequently, it may be challenging to integrate this scale into regular healthcare practice (13).

Few systematic reviews have explored different frailty scales and determined whether frailty assessed by these scales is predictive of all-cause mortality. Furthermore, it remains unclear whether a particular frailty scale is a better predictor of mortality of community-dwelling older adults $(3,6)$. Therefore, the objective of this umbrella review is to qualitatively synthesize and evaluate the association between frailty determined by different frailty scales and all-cause mortality in community-dwelling older people.

\section{Methods}

A protocol was developed, and the review was conducted following the 'Preferred Reporting Items for Systematic reviews and Meta-Analyses' (PRISMA ) statement (14). The protocol was registered at the International Prospective Register of Systematic Reviews or PROSPERO (ID: CRD 42020155407).

\section{Data sources and search strategy}

The search strategy aimed to find published systematic reviews and meta-analyses that evaluated the association between frailty and all-cause mortality in community-dwelling older populations. Systematic and comprehensive searches were conducted in electronic databases: MEDLINE, Embase, PubMed, Cochrane Database of Systematic Reviews (CDSR), Joanna Briggs Institute Evidence-Based Practice (JBI EBP) Database, and Web of Science. The search was conducted in October 2019 and updated in July 2020. The search strategy and search terms are provided in Appendix I. Studies conducted on humans and articles 
published in English were considered eligible for this review, and duplicates were excluded. The searches were independently performed by two authors (ARMSE and CB). Any discrepancies were resolved by discussion.

\section{Inclusion and exclusion criteria}

We included systematic reviews and meta-analyses which have reported the association between frailty and mortality among community-dwelling older adults using any of the frailty scales, e.g., Fried physical frailty phenotype or modifications, deficit accumulation frailty index, and multidomain frailty index. We excluded systematic reviews and meta-analyses. The review included only hospitalized and institutionalized older adults or examined disease-specific outcomes (i.e., falls, fractures, heart failure, etc.) rather than mortality.

\section{Study selection and data extraction}

Two reviewers (ARMSE and CB) independently searched titles. They screened abstracts before retrieving the full texts, assessed eligibility for the type of participants, study design, and outcomes. Data were extracted using a standardized form including author and year of publication, location, population characteristic, sample size, the proportion of female participants, age range, frailty scales used, number of deficits used to create the frailty scales, and follow-up period. We also noted the quality and bias assessment, effect sizes, and measure of variance, most commonly hazard ratios with $95 \%$ confidence intervals and heterogeneity assessments.

\section{Methodological quality assessment}

Manuscripts were assessed for methodological quality before inclusion in the review. The quality assessment of the included five systematic reviews were performed by ARMSE and CB. We used JBI. Critical Appraisal Checklist for Systematic Reviews and Research

Syntheses (15) (Table 1) and online 'A MeaSurement Tool to Assess systematic Reviews Version 2' (AMSTAR 2) checklist (16).

\section{Data synthesis and analysis}

The studies were combined using qualitative best evidence synthesis, as statistical pooling could not be done due to the high heterogeneity of meta-analyses of the included studies. We extracted and reported the pooled effect sizes of the outcomes meta-analyzed within the reviews (Table 2).

\section{Results}

\section{Search results}

A total of 969 records were identified from the six databases, and after removing the duplicates, 686 were screened for eligibility based on title and abstract. Twenty-three full-text articles were then reviewed for relevance, out of which 18 were excluded because aspects similar to, but not defined explicitly as, frailty were assessed, e.g., gait speed $(17,18)$, sarcopenia $(19)$, different health indicators $(20)$ or geriatric syndromes (21); outcomes other than mortality were examined, e.g., trauma (22), fractures $(23,24)$, falls (25), high blood pressure and cardiovascular outcomes (26) or heart failure (27); study population included were from clinical practice (28), nursing home (29) or critical care (30) but not from a community setting; the study involved 
interventions, e.g., treatment modalities (31); or the article was a systematic review protocol or an umbrella review which evaluated frailty scales for clinical outcomes from community, residential care and hospital settings (32-34). This left five eligible systematic reviews and meta-analyses in the umbrella review (Fig. 1).

All five reviews were of moderate to high quality, as assessed by the JBI critical appraisal checklist (Table 1) and online AMSTAR-2 checklist. The reviews included 93 studies (some of which were included in multiple systematic reviews), and they assessed a range of outcomes. Of these studies, 77 examined the association between frailty and all-cause mortality over one to sixteen years of follow-up, and are the focus of this systematic review. Of the five systematic reviews, one review focused only on studies which used exclusively the frailty scale based on the Fried phenotype and its modifications ( 11 scales in a total of which four were original and seven modified) (35); one examined the FRAIL scale which is a questionnaire-based phenotype scale with five components, i.e., fatigue, resistance, ambulation, illness, and loss of weight (2); one review included studies assessing the deficit accumulation frailty index, with between 23 and 70 deficit items (36); one review included studies assessing either the Fried phenotype (7 studies) or the deficit accumulation frailty index (8 studies) (37); while the fifth review included 25 different scales of which five were Fried phenotype-based scales, 14 multidomain scales and six were deficit accumulation frailty index containing 23 to 83 deficits (11).

Table 1. Critical appraisal checklist for systematic reviews and research syntheses (15) 


\begin{tabular}{|c|c|c|c|c|c|c|}
\hline & Items & $\begin{array}{l}\text { Shamliyan } \\
\text { et al. } 2013 \\
\text { (37) }\end{array}$ & $\begin{array}{l}\text { Chang } \\
\text { et al. } \\
2015 \\
(35) \\
\end{array}$ & $\begin{array}{l}\text { Vermerien } \\
\text { et al. } 2016 \\
\text { (11) }\end{array}$ & $\begin{array}{l}\text { Kojima et } \\
\text { al. } 2018 \\
(36)\end{array}$ & $\begin{array}{l}\text { Kojima G. } \\
2018 \text { (2) }\end{array}$ \\
\hline 1 & $\begin{array}{l}\text { Is the review question } \\
\text { clearly and explicitly } \\
\text { stated? }\end{array}$ & Yes & Yes & Yes & Yes & Yes \\
\hline 2 & $\begin{array}{l}\text { Were the inclusion } \\
\text { criteria appropriate for } \\
\text { the review question? }\end{array}$ & Yes & Yes & No & No & No \\
\hline 3 & $\begin{array}{l}\text { Was the search strategy } \\
\text { appropriate? }\end{array}$ & Yes & Yes & Yes & Yes & Yes \\
\hline 4 & $\begin{array}{l}\text { Were the sources and } \\
\text { resources used to } \\
\text { search for studies } \\
\text { adequate? }\end{array}$ & Yes & Yes & Yes & Yes & Yes \\
\hline 5 & $\begin{array}{l}\text { Were the criteria for } \\
\text { appraising studies } \\
\text { appropriate? }\end{array}$ & Yes & Yes & Yes & Yes & Yes \\
\hline 6 & $\begin{array}{l}\text { Did two or more } \\
\text { reviewers conduct } \\
\text { critical appraisal } \\
\text { independently? }\end{array}$ & Yes & $\begin{array}{l}\text { Yes } \\
\text {. }\end{array}$ & Yes & No & Yes \\
\hline 7 & $\begin{array}{l}\text { Were the methods } \\
\text { used to combine } \\
\text { studies appropriate? }\end{array}$ & Yes & Yes & Yes & Yes & Yes \\
\hline 8 & $\begin{array}{l}\text { Were there methods to } \\
\text { minimize errors in } \\
\text { data extraction }\end{array}$ & Yes & Yes & Yes & Yes & Yes \\
\hline 9 & $\begin{array}{l}\text { Was the likelihood of } \\
\text { publication bias } \\
\text { assessed? }\end{array}$ & $\begin{array}{l}\text { Not } \\
\text { mentioned }\end{array}$ & Yes & $\begin{array}{l}\text { Not } \\
\text { mentioned }\end{array}$ & Yes & Yes \\
\hline 10 & $\begin{array}{l}\text { Were recommendations } \\
\text { for policy or practice } \\
\text { supported by the } \\
\text { reported data? }\end{array}$ & Yes & Yes & Yes & $\begin{array}{l}\text { Not } \\
\text { mentioned }\end{array}$ & $\begin{array}{l}\text { Not } \\
\text { mentioned }\end{array}$ \\
\hline 11 & $\begin{array}{l}\text { Were the specific } \\
\text { directives for new } \\
\text { research appropriate? }\end{array}$ & Yes & Yes & Yes & Yes & Yes \\
\hline
\end{tabular}

Overall, the participants were predominantly over 65 years of age, with a minimum age for inclusion varying from 50 to 75 . However, one study included participants with a minimum age of 15 years (38). The maximum age recorded in one study was 108 years (36). The participants included were community-dwelling individuals from Australia, Canada, China, Israel, Mexico, the United Kingdom (UK), the United States of America (USA), and multiple European countries. Female participants represented $42-74 \%$ of the sample in most studies (Table 2). Individual study's frailty outcome was adjusted for a range of two to ten covariates (e.g., age, gender, education, smoking, alcohol intake, socioeconomic conditions) in their analysis.

Table 2: Summary characteristics of the included systematic reviews and meta-analyses 


\begin{tabular}{|c|c|c|c|c|c|}
\hline Characteristics & $\begin{array}{l}\text { Shamliyan et } \\
\text { al. } 2013 \text { (37) }\end{array}$ & $\begin{array}{l}\text { Chang et al. } 2015 \\
(35)\end{array}$ & $\begin{array}{l}\text { Vermeiren et } \\
\text { al. } 2016 \text { (11) }\end{array}$ & \begin{tabular}{|l|} 
Kojima et \\
al. 2018 \\
$(36)$
\end{tabular} & $\begin{array}{l}\text { Kojima G. } \\
2018 \\
(2)\end{array}$ \\
\hline $\begin{array}{l}\text { No. of studies } \\
\text { (n); countries; } \\
\text { no. of } \\
\text { participants } \\
\text { (n) }\end{array}$ & $\begin{array}{l}24 ; \\
\text { Australia, } \\
\text { Canada, } \\
\text { China, } \\
\text { France, } \\
\text { Netherlands, } \\
\text { Sweden and } \\
\text { USA; 72,052 }\end{array}$ & $\begin{array}{l}\text { 11; Finland, France, } \\
\text { Israel, Spain and USA; } \\
35,538\end{array}$ & $\begin{array}{l}31 ; \\
\text { Australia, } \\
\text { Canada, } \\
\text { China, } \\
\text { France, } \\
\text { Netherlands } \\
\text { and U.S.A.; } \\
150,763\end{array}$ & $\begin{array}{l}\text { 19; Canada, } \\
\text { China, } \\
\text { Europe, } \\
\text { Netherlands, } \\
\text { U.K. and } \\
\text { U.S.A.; } \\
121,634\end{array}$ & $\begin{array}{l}\text { 8; } \\
\text { Australia, } \\
\text { Europe, } \\
\text { Hong } \\
\text { Kong, } \\
\text { Mexico, } \\
\text { U.K. and } \\
\text { U.S.A.; } \\
\text { 54,128 }\end{array}$ \\
\hline $\begin{array}{l}\text { Mortality } \\
\text { evaluated } \\
\text { in studies } \\
\text { (n) }\end{array}$ & 15 studies & 11 studies & 24 studies & $\begin{array}{l}19 \text { studies; All } \\
\text { DAFI }\end{array}$ & $\begin{array}{l}\text { Eight } \\
\text { studies; } \\
\text { All FRAIL }\end{array}$ \\
\hline $\begin{array}{l}\text { Characteristics } \\
\text { of participants } \\
\text { age range }(y) ; \\
\% \text { female }\end{array}$ & $\begin{array}{l}65+\text { years; } \\
42- \\
73 \% \text { (8 } \\
\text { studies), } \\
\text { three 100\%, } \\
\text { four } \\
0 \%\end{array}$ & $\begin{array}{l}\text { 65+ years; Not } \\
\text { mentioned \% } \\
\text { (8 studies), one } 100 \% \text {, } \\
\text { two } 0 \%\end{array}$ & $\begin{array}{l}65+\text { years; } \\
49- \\
74 \% \text { (15 } \\
\text { studies), } \\
\text { two 100\%, } \\
\text { one } \\
0 \% \text {, NA (6 } \\
\text { studies) }\end{array}$ & $\begin{array}{l}18 \text { to } 108 \\
\text { years; } \\
51-68 \%(13 \\
\text { studies), } \\
\text { three } 10 \% \text {, } \\
\text { three } 0 \%\end{array}$ & $\begin{array}{l}49 \text { to } 104 \\
\text { years; } \\
50 \text { to } 55 \% \\
\text { (3 } \\
\text { studies), } \\
\text { two } 100 \%, \\
\text { three } 0 \% .\end{array}$ \\
\hline $\begin{array}{l}\text { Frailty } \\
\text { scales used }\end{array}$ & $\begin{array}{l}15 \text { different } \\
\text { scales; } 7 \\
\text { Phenotype; } 8 \\
\text { DAFI with } \\
36 \text { to } \\
71 \text { deficits }\end{array}$ & $\begin{array}{l}\text { All Fried phenotype } \\
\text { scales; } 4 \\
\text { original, seven modified }\end{array}$ & $\begin{array}{l}\text { 25 scales; } 5 \\
\text { Fried } \\
\text { phenotype, } \\
14 \\
\text { MDFI, } 6 \\
\text { DAFI } \\
\text { with } 23 \text { to } \\
83 \\
\text { deficits }\end{array}$ & $\begin{array}{l}\text { All DAFI; } 23 \\
\text { to } 70 \text { deficits }\end{array}$ & $\begin{array}{l}\text { All FRAIL } \\
\text { scales }\end{array}$ \\
\hline $\begin{array}{l}\text { Quality \& } \\
\text { bias } \\
\text { assessment }\end{array}$ & AHRQ guide & AHRQ guide & $\begin{array}{l}\text { NICE } \\
\text { checklists }\end{array}$ & QUADAS-2 & N.O.S. \\
\hline $\begin{array}{l}\text { Main findings: } \\
\text { H.R. (95\% } \\
\text { CI) unless } \\
\text { stated }\end{array}$ & $\begin{array}{l}\text { RR: Fried: F } \\
\text { VS R 1.50 } \\
\text { (95\% CI } \\
\text { NA); } \\
\text { DAFI: F vs R } \\
1.15(95 \% \\
\text { CI NA) } \\
\text { Predictive } \\
\text { value: across } \\
\text { frailty } \\
\text { definitions } \\
\sim 70 \% \text { in } \\
\text { R.O.C. } \\
\text { curve areas }\end{array}$ & $\begin{array}{l}\text { F vS R: } 2.00(1.73,- \\
2.32) ; \text { PF vs R: } 1.34 \\
(1.26,1.41) ; \\
\text { F Vs P.F.: } 1.48 \\
(1.34,1.63)\end{array}$ & $\begin{array}{l}\text { Overall: F vs } \\
\text { R } 2.34 \\
\text { (1.77, } 3.09) ; \\
\text { RR: F vs R } \\
1.83 \\
(1.68,1.98) \\
\text { Fried: F vs R } \\
2.58 \text { (1.83, } \\
\text { 3.64); MDFI: } \\
\text { F VS R } 2.13 \\
\text { (1.38, 3.29); } \\
\text { DAFI: F vs R } \\
1.85 \text { (1.30, } \\
2.63)\end{array}$ & $\begin{array}{l}13 \text { cohorts, all } \\
\text { per } 0.1 \\
\text { increase } \\
\text { in FI: } 1.04 \\
(1.03- \\
1.04) \text {; } \\
6 \text { cohorts: } \\
1.28(1.26- \\
1.31)\end{array}$ & $\begin{array}{l}\text { F vS R: } \\
3.53 \\
(1.66, \\
7.49) ; \mathrm{F} \\
\text { vs PF: } \\
1.75 \\
(1.14, \\
2.70) ; \\
\text { Predictive } \\
\text { value: } 54 \% \\
\text { to } 70 \% \text { in } \\
\text { ROC curve } \\
\text { areas }\end{array}$ \\
\hline $\begin{array}{l}\text { Follow-up } \\
\text { period }\end{array}$ & 3 to 5 years & 4 to 10 years & 1 to 9 years & 2 to 14 years & \begin{tabular}{|l|}
2 to 16 \\
years
\end{tabular} \\
\hline $\begin{array}{l}\text { Heterogeneity } \\
\text { (Statistical, S } \\
\text { and clinical, C) }\end{array}$ & $\begin{array}{l}\text { S: sig } \\
\text { heterogen; } \\
\text { C: No }\end{array}$ & S: sig heterogen; C: No & $\begin{array}{l}\text { S: sig } \\
\text { heterogen; } \\
\text { C: No }\end{array}$ & $\begin{array}{l}\text { S: sig } \\
\text { heterogen; C: } \\
\text { Yes (E.D.) }\end{array}$ & $\begin{array}{l}\text { S: sig } \\
\text { heterogen; } \\
\text { C: No }\end{array}$ \\
\hline $\begin{array}{l}\text { Publication } \\
\text { bias assessed }\end{array}$ & $\begin{array}{l}\text { Not } \\
\text { mentioned }\end{array}$ & $\begin{array}{l}\text { No bias (funnel plot, } \\
\text { Egger's test) }\end{array}$ & $\begin{array}{l}\text { Not } \\
\text { mentioned }\end{array}$ & $\begin{array}{l}\text { No bias } \\
\text { (Funnel plot; } \\
\text { Begg- } \\
\text { Mazumdar's } \\
\text { test) }\end{array}$ & $\begin{array}{l}\text { No bias } \\
\text { (Funnel } \\
\text { plots) }\end{array}$ \\
\hline
\end{tabular}

Abbreviations: 95\% CI: 95\% confidence interval; AHRQ: Agency for Healthcare Research and Quality; AMSTAR 2: A MeaSurement Tool to Assess systematic Reviews 2; A.U.C.: Area under 
the R.O.C. Curve; DAFI: Deficit Accumulation Frailty Index; E.D.: Emergency Department; F: Frail; H.R.: Hazard ratio; NICE: National Institute for Health and Care Excellence; N.O.S.: Newcastle-Ottawa Scale; OR: Odds ratio; P.A.R.: Population Attributable Risk; P.F.: Prefrail; QUADAS-2: Quality Assessment Tool for Diagnostic Accuracy Studies; R: Robust; R.O.C.: Receiver operating characteristic curve; R.R.: Relative risk

\section{Overall findings for the association between frailty and all-cause mortality}

All five systematic reviews reported a significant association between frailty and an increased risk of mortality; however, the effect size between frailty and mortality varied across the included systematic reviews. For example, the meta-analysis that included 24 studies using three types of scales (i.e., Fried physical frailty phenotype, deficit accumulation frailty index, and multidomain frailty index) estimated an overall hazard ratio $2.34(95 \% \mathrm{Cl}: 1.77,3.09)$ between frailty and all-cause mortality $(11)$. The estimated overall relative risk was 1.83 (95\% Cl: 1.68, 1.98). In their analysis, comparing the non-frail to frail groups, the risk associated with mortality varied depending on the frailty scales used. The Fried physical frailty phenotype was associated with a 2.6 -fold increased risk of mortality (HR: $2.58 ; 95 \% \mathrm{Cl}: 1.83,3.64 ; \mathrm{I}^{2}=89 \%, \mathrm{P}$ $<0.001$ ); the multidomain frailty index with a 2.1 -fold increased risk (HR: $2.13 ; 95 \% \mathrm{Cl}: 1.38,3.29 ; \mathrm{I}^{2}=96 \%, \mathrm{P}$ $<0.001)$; and the deficit accumulation frailty index a 1.85 -fold (HR:1.85; $95 \% \mathrm{Cl}: 1.30,2.63 ;\left.\right|^{2}=$ not available, $\mathrm{P}=$ not available) (11). Similar effect sizes were reported from the systematic review that included only the phenotype-based frailty index and found that frailty was associated with a two-fold increased risk of mortality than robust or non-frail persons (HR: 2.00; $95 \%$ Cl: 1.73, 2.32) (35). Direct comparison of effect sizes from the other systematic review was not possible, given they considered the association between a one-unit increase in frailty score using the deficit accumulation frailty index and mortality (random effect model: HR:1.04; 95\% Cl: 1.03, 1.04; fixed effect model: HR: 1.28; 95\% Cl: 1.26, 1.31 per 0.1 increase in frailty index) (36). Only one systematic review included a questionnaire-based FRAIL scale to assess the relationship between frailty and mortality (2). From the eight studies included in this review, it was found that individuals classified as frail or prefrail, compared to non-frail individuals, had a 3.5 -fold and 1.8-fold increased risk of mortality, respectively, over 2.4 years to 4.3 years of follow-up. The predictive value of mortality remained similar across definitions of frailty, ranging from $54-70 \%$ in the receiver operating characteristic curve areas using a questionnaire-based FRAIL scale (2) and remained around $70 \%$ if the Fried physical frailty phenotype or the deficit accumulation frailty index were used (37).

\section{Gender differences}

Three of the five reviews examined potential gender differences in the association between frailty and mortality and yielded some conflicting results (35-37). For example, one review using the Fried physical frailty phenotype and another using the deficit accumulation frailty scale showed that older men with frailty had a higher risk of mortality than older women with frailty $(35,36)$. However, the third review (37) found mixed results depending on the individual study, with some reporting that men had an increased risk of mortality (39-42). Still, others found that women had an increased risk (41-43). One study reported a doseresponse association between a more significant number of deficits and increased mortality in women across all age categories (41). However, this review (37) did not directly compare the risk between gender.

\section{Age}


Age did not appear to be an effect modifier of the relationship between frailty assessed using the Fried physical frailty phenotype or deficit accumulation index, and mortality. Two of the five systematic reviews examined the association between frailty and mortality according to age groups $(35,36)$. The pooled estimates showed that the association between the deficit accumulation index and mortality did not vary between those aged below 65 years (HR:1.05; 95\% Cl: 1.03, 1.07) and those above 65 years (HR:1.04; 95\% Cl:1.03, 1.05) (36) per unit increase in a frailty index. Likewise, mortality risk was similar for those aged below 80 years (HR:1.62; 95\% Cl:1.39, 1.89) and above 80 years (HR:1.41; 95\% Cl:1.17, 1.70) estimated by the Fried physical frailty phenotype (35). Three other systematic reviews did not compare mortality based on age stratification $(2,11,37)$.

\section{Follow-up duration}

The association between frailty and mortality varied according to follow-up duration. The risk of mortality was the lowest when the follow-up period was less than 12 months (HR:1.33; 95\% Cl:1.11, 1.60) and was the highest when the follow-up period was between two years to five years (HR: $3.25 ; 95 \% \mathrm{Cl}: 2.14,4.94)(11)$. However, another review using the deficit accumulation frailty index found that the risk of mortality was higher when a shorter follow-up time was examined than a more extended follow-up, but effect sizes are not mentioned (36). Likewise, one systematic review compared a follow-up time of 4 years versus 11 years and observed that the strongest association between frailty and mortality was in the shorter follow-up group. However, individual values were not provided (37).

\section{Discussion}

There is increasing interest in frailty as a clinically meaningful measure of geriatric health condition, and the number of publications on frailty has increased exponentially over the last few decades $(5,44)$.

Determination of frailty status is emerging as a significant predictor of outcomes in various medical disciplines, including cardiology $(27,45)$, neurology $(46,47)$, oncology $(48)$, orthopedics $(23)$, and surgery (49), as well as the senior population in general. Accordingly, the association between frailty and all-cause mortality has been investigated across different settings and populations. We identified five moderate to high quality large systematic reviews examining three major categories of frailty scales and the association with all-cause mortality in community-dwelling older individuals.

This umbrella review included 93 primary studies comprising 434,115 participants from Australia, Canada, China, Hong Kong, Mexico, the UK, the USA and multiple other European countries. A total of 80 different frailty scales were used across the different studies, ranging from Fried physical frailty phenotype and various modifications of this scale to multidomain scales and the deficit accumulation frailty index of included deficits ranging from 23 to 83 . The follow-up period ranged from 12 months to 16 years. A large number of community-dwelling participants across the world means that the outcomes of this study can be more widely generalized to older individuals. Heterogeneity in frailty definitions, scales, adjustment strategies (37), different population groups, different follow-up periods (11), and modifications of the phenotype scale (35) hampered the synthesis of evidence. Only one review (36) exclusively examined deficit accumulation frailty index and mortality. In that review, many primary studies were excluded because they did not provide effect size for mortality. The effect measures available were based on frailty groups defined by different cut- 
off points. The review of studies using the questionnaire-based FRAIL scale also described moderate to high heterogeneity; furthermore, the FRAIL scale was relatively newer and only included a limited number of primary studies in the meta-analysis (2).

The extent to which the different frailty scales predict mortality was a consideration of this umbrella review. However, only two of the five systematic reviews estimated the predictability of the included frailty scales, showing similar predictive value across definitions of frailty. One review (37) compared the survival estimates based on age and adjusted relative risk using both the Fried physical frailty phenotype and the deficit accumulation frailty index. They found that frail older adult, compared to non-frail older adults defined using the Fried phenotype, had an approximate $50 \%$ increase in mortality risk while studies using the deficit accumulation index reported an approximate 15\% increase in risk. A similar predictive value was observed across definitions of frailty, averaging around $70 \%$ in receiver operating characteristic curve areas (37). It is hard to directly compare predictive value across frailty measures, as only two studies directly assessed this. However, the results of these studies showed that the receiver operating characteristic curve ranged from 0.54 to $0.70(2,37)$.

\section{Strengths And Limitations}

The current umbrella review has multiple strengths. The protocol was registered at PROSPERO, and the PRISMA guidelines were followed in completing this review. The search strategy of the review was robust and reproducible and utilized comprehensive search terms in multiple electronic databases. We evaluated five moderates to high-quality systematic reviews, which examined many participants from different parts of the world. Therefore, the generalizability of the results is high. We included systematic reviews that measured frailty using the commonly available scales, i.e., Fried physical frailty phenotype, multidomain frailty scale (including the questionnaire-based FRAIL scale), and deficit accumulation frailty index, meaning the findings will be relevant more broadly.

However, there are some limitations. This umbrella review did not include intervention studies, or systematic reviews of frail participants from hospitals or nursing homes were excluded. Thus, the findings apply to community-dwelling older individuals only.

For researchers, this umbrella review shows that any category of frailty scale has utility for predicting mortality. Finally, this umbrella review focussed on the utility of frailty assessment to predict mortality though it could be considered that delaying mortality is not the only or best objective for the geriatric population. Improving the quality of life before death or extending life free of disability could be considered as the critical outcomes for assessing risk in those who are frail, possibly a future analysis.

\section{Conclusion}

The findings of this review provide satisfactory evidence that frailty is associated with mortality risk, and thus highlight the importance of assessing frailty in primary community settings. This umbrella review has demonstrated that frailty is a significant predictor of all-cause mortality regardless of the specific frailty scale. For example, frailty assessed using five components that excludes cognition and affect (Fried physical 
frailty phenotype) predicted mortality to a similar extent as did more comprehensive deficit accumulation frailty indices that included up to 83 items. As such, this implies that researchers and clinicians can use the most appropriate frailty scales given their circumstances, resources, and access to information. Together these findings emphasize that the assessment of frailty status itself may be more important than the choice of which type of scale is used.

\section{List Of Abbreviations}

AMSTAR-2: A MeaSurement Tool to Assess systematic Reviews Version 2

CDSR: Cochrane Database of Systematic Reviews

FRAIL: Fatigue, Resistance, Ambulation, Illness, and Loss of weight

HR: Hazard Ratio

JBI: Joanna Briggs Institute

OR: Odds Ratio

PRISMA: Preferred Reporting Items for Systematic Reviews and Meta-Analyses

PROSPERO: International Prospective Register of Systematic Reviews

RR: Relative Risk

\section{Declarations}

Ethics approval and consent to participate: It was not requested being a review of already published literature Consent for publication: Not applicable

Availability of data and materials: The datasets generated during the current study are available from the corresponding author

Competing interests: The authors declare that they have no competing interests

Funding: Not funded

Authors' contributions: ARMSE developed the idea, searched the literature, reviewed articles, extracted data, and contributed to writing. CB searched and reviewed the literature. RLW, SEE, ME, and JR reviewed, edited, and contributed to writing. All authors read and approved the final manuscript.

Acknowledgments: Not applicable

Footnotes: Not applicable 


\section{References}

1. Fried LP, Hadley EC, Walston JD, Newman AB, Guralnik JM, Studenski S, et al. From bedside to bench: research agenda for frailty. Sci Aging Knowledge Environ. 2005;2005(31):pe24.

2. Kojima G. Frailty Defined by FRAIL scale as a Predictor of Mortality: A Systematic Review and Metaanalysis. J Am Med Dir Assoc. 2018;19(6):480-3.

3. Fried LP, Tangen CM, Walston J, Newman AB, Hirsch C, Gottdiener J, et al. frailty in older adults: evidence for a phenotype. J Gerontol A Biol Sci Med Sci. 2001;56(3):M146-56.

4. Kulmala J, Nykanen I, Hartikainen S. Frailty as a predictor of all-cause mortality in older men and women. Geriatrics and Gerontology International. 2014;14(4):899-905.

5. Ofori-Asenso R, Chin KL, Mazidi M, Zomer E, Ilomaki J, Zullo AR, et al. Global Incidence of Frailty and Prefrailty Among Community-Dwelling Older Adults: A Systematic Review and Meta-analysisGlobal Incidence of Frailty and Prefrailty Among Community-Dwelling Older AdultsGlobal Incidence of Frailty and Prefrailty Among Community-Dwelling Older Adults. JAMA Network Open. 2019;2(8):e198398-e.

6. Lunenfeld B, Stratton P. The clinical consequences of an ageing world and preventive strategies. Best Practice \& Research in Clinical Obstetrics \& Gynaecology. 2013;27(5):643-59.

7. Morley JE, Vellas B, van Kan GA, Anker SD, Bauer JM, Bernabei R, et al. Frailty consensus: a call to action. Journal of the American Medical Directors Association. 2013;14(6):392-7.

8. Veronese N. Frailty as Cardiovascular Risk Factor (and Vice Versa). Adv Exp Med Biol. 2020;1216:51-4.

9. Rockwood K, Mitnitski A, Song X, Steen B, Skoog I. Long-term risks of death and institutionalization of elderly people in relation to deficit accumulation at age 70 . Journal of the American Geriatrics Society. 2006;54(6):975-9.

10. Xue QL. The frailty syndrome: definition and natural history. Clin Geriatr Med. 2011;27(1):1-15.

11. Vermeiren S, Vella-Azzopardi R, Beckwee D, Habbig AK, Scafoglieri A, Jansen B, et al. Frailty and the Prediction of Negative Health Outcomes: A Meta-Analysis. Journal of the American Medical Directors Association. 2016;17(12):1163.e1-.e17.

12. Rockwood K, Song X, MacKnight C, Bergman H, Hogan DB, McDowell I, et al. A global clinical measure of fitness and frailty in elderly people. CMAJ Canadian Medical Association Journal. 2005;173(5):489-95.

13. Mitnitski AB, Mogilner AJ, Rockwood K. Accumulation of deficits as a proxy measure of aging. ScientificWorldJournal. 2001;1:323-36.

14. Liberati A, Altman DG, Tetzlaff J, Mulrow C, Gøtzsche PC, loannidis JP, et al. The PRISMA statement for reporting systematic reviews and meta-analyses of studies that evaluate healthcare interventions: explanation and elaboration. Bmj. 2009;339:b2700.

15. Aromataris E, Fernandez R, Godfrey CM, Holly C, Khalil H, Tungpunkom P. Summarizing systematic reviews. International Journal of Evidence-Based Healthcare. 2015;13(3):132-40.

16. Shea BJ, Reeves BC, Wells G, Thuku M, Hamel C, Moran J, et al. AMSTAR 2: a critical appraisal tool for systematic reviews that include randomised or non-randomised studies of healthcare interventions, or both. BMJ. 2017;358:j4008. 
17. Houles M, Abellan Van Kan G, Rolland Y, Andrieu S, Anthony P, Bauer J, et al. Gait speed at usual pace as a predictor of adverse outcomes in community-dwelling older people. [French]. Cahiers de l'Annee Gerontologique. 2010;2(1):13-23.

18. Abellan van Kan G, Rolland Y, Andrieu S, Bauer J, Beauchet O, Bonnefoy M, et al. Gait speed at usual pace as a predictor of adverse outcomes in community-dwelling older people an International Academy on Nutrition and Aging (IANA) Task Force. J Nutr Health Aging. 2009;13(10):881-9.

19. Chang SF, Lin PL. Systematic Literature Review and Meta-Analysis of the Association of Sarcopenia With Mortality. Worldviews Evid Based Nurs. 2016;13(2):153-62.

20. Kusumastuti S, Rozing MP, Lund R, Mortensen EL, Westendorp RGJ. The added value of health indicators to mortality predictions in old age: A systematic review. Eur J Intern Med. 2018;57:7-18.

21. Kane RL, Shamliyan T, Talley K, Pacala J. The association between geriatric syndromes and survival. Journal of the American Geriatrics Society. 2012;60(5):896-904.

22. Poulton A, Shaw JF, Nguyen F, Wong C, Lampron J, Tran A, et al. The Association of Frailty With Adverse Outcomes After Multisystem Trauma: A Systematic Review and Meta-analysis. Anesth Analg. 2020;130(6):1482-92.

23. Chen KW, Chang SF, Lin PL. Frailty as a Predictor of Future Fracture in Older Adults: A Systematic Review and Meta-Analysis. Worldviews Evid Based Nurs. 2017;14(4):282-93.

24. Xu BY, Yan S, Low LL, Vasanwala FF, Low SG. Predictors of poor functional outcomes and mortality in patients with hip fracture: a systematic review. BMC Musculoskelet Disord. 2019;20(1):568.

25. Cheng $\mathrm{MH}$, Chang SF. Frailty as a Risk Factor for Falls Among Community Dwelling People: Evidence From a Meta-Analysis. J Nurs Scholarsh. 2017;49(5):529-36.

26. Zhang XE, Cheng B, Wang Q. Relationship between high blood pressure and cardiovascular outcomes in elderly frail patients: A systematic review and meta-analysis. Geriatr Nurs. 2016;37(5):385-92.

27. Zhang Y, Yuan M, Gong M, Tse G, Li G, Liu T. Frailty and Clinical Outcomes in Heart Failure: A Systematic Review and Meta-analysis. J Am Med Dir Assoc. 2018;19(11):1003-8.e1.

28. Abellan van Kan G, Rolland Y, Bergman H, Morley JE, Kritchevsky SB, Vellas B. The IAN.A Task Force on frailty assessment of older people in clinical practice. J Nutr Health Aging. 2008;12(1):29-37.

29. Zhang X, Dou Q, Zhang W, Wang C, Xie X, Yang Y, et al. Frailty as a Predictor of All-Cause Mortality Among Older Nursing Home Residents: A Systematic Review and Meta-analysis. J Am Med Dir Assoc. 2019;20(6):657-63.e4.

30. Pugh R, John DL, Thorpe C, Subbe C. Frailty measures in the critically ill: are we approaching a critical age? A systematic review. Crit Care. 2014;18(Suppl 1):P50-P.

31. Van der Elst M, Schoenmakers B, Duppen D, Lambotte D, Fret B, Vaes B, et al. Interventions for frail community-dwelling older adults have no significant effect on adverse outcomes: a systematic review and meta-analysis. BMC Geriatr. 2018;18(1):249.

32. Moraes MB, Araujo CFM, Avgerinou C, Vidal EIO. Nutritional interventions for the treatment of frailty in older adults: a systematic review protocol. Medicine (Baltimore). 2018;97(52):e13773.

33. Shears M, McGolrick D, Waters B, Jakab M, Boyd JG, Muscedere J. Frailty measurement and outcomes in interventional studies: protocol for a systematic review of randomised control trials. BMJ Open. 
2017;7(12):e018872.

34. Apostolo J, Cooke R, Bobrowicz-Campos E, Santana S, Marcucci M, Cano A, et al. Predicting risk and outcomes for frail older adults: an umbrella review of frailty screening tools. JBI Database Of Systematic Reviews And Implementation Reports. 2017;15(4):1154-208.

35. Chang SF, Lin PL. Frail phenotype and mortality prediction: a systematic review and meta-analysis of prospective cohort studies. Int J Nurs Stud. 2015;52(8):1362-74.

36. Kojima G, Iliffe S, Walters K. Frailty index as a predictor of mortality: a systematic review and metaanalysis. Age and ageing. 2018;47(2):193-200.

37. Shamliyan T, Talley KM, Ramakrishnan R, Kane RL. Association of frailty with survival: a systematic literature review. Ageing Res Rev. 2013;12(2):719-36.

38. Rockwood K, Song X, Mitnitski A. Changes in relative fitness and frailty across the adult lifespan: evidence from the Canadian National Population Health Survey. Cmaj. 2011;183(8):E487-94.

39. Cawthon PM, Marshall LM, Michael Y, Dam TT, Ensrud KE, Barrett-Connor E, et al. Frailty in older men: prevalence, progression, and relationship with mortality. Journal of the American Geriatrics Society. 2007;55(8):1216-23.

40. Ensrud KE, Ewing SK, Cawthon PM, Fink HA, Taylor BC, Cauley JA, et al. A comparison of frailty indexes for the prediction of falls, disability, fractures, and mortality in older men. Journal of the American Geriatrics Society. 2009;57(3):492-8.

41. Gu D, Dupre ME, Sautter J, Zhu H, Liu Y, Yi Z. Frailty and Mortality Among Chinese at Advanced Ages. The Journals of Gerontology: Series B. 2009;64B(2):279-89.

42. Puts MTE, Lips P, Deeg DJH. Sex Differences in the Risk of Frailty for Mortality Independent of Disability and Chronic Diseases. Journal of the American Geriatrics Society. 2005;53(1):40-7.

43. Bandeen-Roche K, Xue Q-L, Ferrucci L, Walston J, Guralnik JM, Chaves P, et al. Phenotype of Frailty: Characterization in the Women's Health and Aging Studies. The Journals of Gerontology: Series A. 2006;61(3):262-6.

44. Buckinx F, Rolland Y, Reginster J-Y, Ricour C, Petermans J, Bruyère 0 . Burden of frailty in the elderly population: perspectives for a public health challenge. Arch Public Health. 2015;73(1):19-.

45. Stewart R. Cardiovascular Disease and Frailty: What Are the Mechanistic Links? Clin Chem. 2019;65(1):80-6.

46. Evans NR, Wall J, To B, Wallis SJ, Romero-Ortuno R, Warburton EA. Clinical frailty independently predicts early mortality after ischaemic stroke. Age and ageing. 2020;49(4):588-91.

47. Taylor-Rowan M, Cuthbertson G, Keir R, Shaw R, Drozdowska B, Elliott E, et al. The prevalence of frailty among acute stroke patients, and evaluation of method of assessment. Clin Rehabil. 2019;33(10):168896.

48. Ethun CG, Bilen MA, Jani AB, Maithel SK, Ogan K, Master VA. Frailty and cancer: Implications for oncology surgery, medical oncology, and radiation oncology. CA Cancer J Clin. 2017;67(5):362-77.

49. Maxwell CA, Patel MB, Suarez-Rodriguez LC, Miller RS. Frailty and Prognostication in Geriatric Surgery and Trauma. Clin Geriatr Med. 2019;35(1):13-26. 
50. Moher D, Liberati A, Tetzlaff J, Altman DG, The PG. Preferred Reporting Items for Systematic Reviews and Meta-Analyses: The PRISMA Statement. PLOS Medicine. 2009;6(7):e1000097.

\section{Figures}

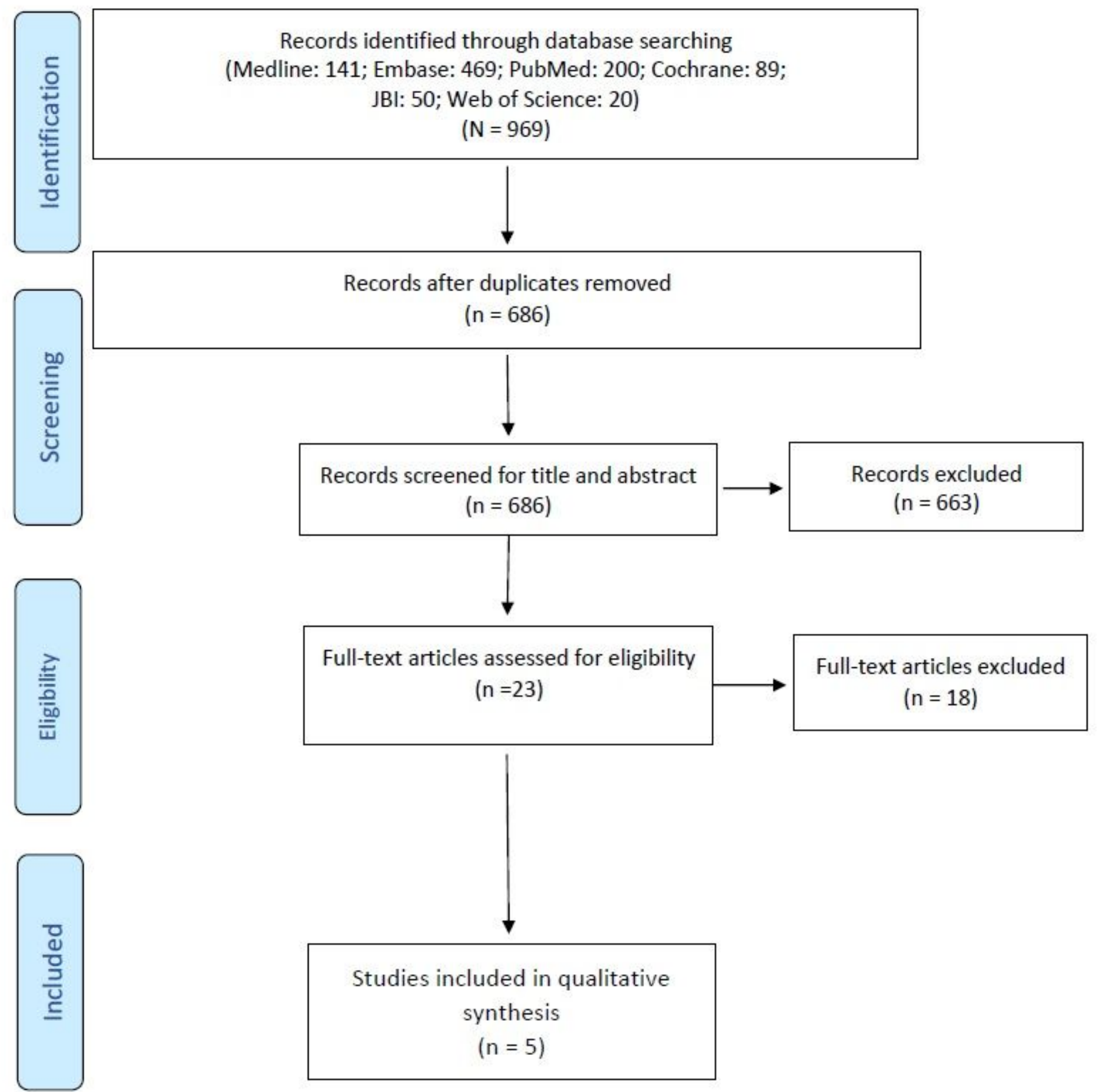

Figure 1

PRISMA 2009 Flow Diagram (50): Frailty Status and All-Cause Mortality in Community-Dwelling Older Individuals: An Umbrella Review 


\section{Supplementary Files}

This is a list of supplementary files associated with this preprint. Click to download.

- AppendixISearchstartegyFrailtyandMortalityUR.pdf

- AppendixllExcludedSystematicReviews.pdf 